\title{
Noise Exposure, Awareness, Practice and Noise Annoyance Among Steel Workers in United Arab Emirates
}

\author{
Hafiz Omer Ahmed*
}

Department of Environmental Health, College of Health Sciences, University of Sharjah, P.O. Box 27272, United Arab

Emirates (UAE)

\begin{abstract}
This cross-sectional study investigated noise annoyance, awareness and practice among the workers in two steel factories in UAE. The study involving 468 steel workers randomly selected. Noise exposure was estimated using the integrated sound level meter. A structured interview questionnaire was used to assess the noise annoyance, awareness and practice of workers towards the noise. The results showed that about $89 \%$ of the workers exposed to a daily Leq above the permissible level which is $85 \mathrm{~dB}(\mathrm{~A})$ and $45 \%$ of them had never used any hearing protection devices. About $58 \%$ of the workers experienced a moderate or high degree of noise annoyance. Only $4.1 \%$ and $1.9 \%$ of the workers aware about the health effects of noise and the methods of prevention respectively and awareness was positively associated with noise exposure. Few workers (13.2\%) used the hearing protection devices during the working time. Thus workers within both factories are at high risk of developing noise annoyance, and other related ailments due to excessive occupational exposure to noise, and non-use of hearing protection devices. There was an association between noise annoyance and noise level and any one of them could influence the workers to use the hearing protection devices. There is a need to have a hearing conservation program in both factories one of its main components is education to raise the awareness of workers about noise hazards and methods of prevention. Finally, the factor noise annoyance should be incorporated into all future studies on the use of hearing protection devices.
\end{abstract}

Keywords: Annoyance, Awareness and practice, Noise exposure, Steel factory.

\section{INTRODUCTION}

Occupational exposure to excessive noise has been identified as a very prominent hazard encountered in steel factories all over the world. Noise induced hearing loss (NIHL) as a result of exposure to high noise levels is well documented in the literature [1-6]. In addition, exposure to excessive noise also leads to non-auditory effects including: annoyance, masking of warning signals resulting in accidents, interfering with communications among the workers, increasing the blood pressure of the exposed workers, and affecting the performance of the workers [7, 8]. However, few studies have addressed these non-auditory among workers in developing countries.

In UAE, the rate of industrialization has increased significantly over the past decades and many industries have been established. Many within the workforce of these industries were and are exposed to occupational hazards and consequently are at high risk of work-related diseases and injuries. However, the relevant authorities in the UAE are concerned about the hazards of such industries and the need for implementing effective safety measures for the prevention of possible adverse health effects. Legislation has been in place for over 25 years. However, the level of implementation varies significantly across the industrial sectors [9].

*Address correspondence to this author at the Department of Environmental Health, College of Health Sciences, University of Sharjah, P.O. Box 27272, United Arab Emirates (UAE); Tel: +97165057507, +971504932075; Fax:+97165057502; E-Mails: hafizomer@sharjah.ac.ae;

hafizoahmed@yahoo.com
Control measures at source, path and persons exposed to hazards are the ideal means of preventing occupational diseases and injuries among workers. However, workers' awareness and knowledge about jobs associated hazards and personal protective equipment will reduce risks of some occupational hazards.

The main objectives of this study were: to estimate levels of noise and compare it with the standards, to determine the prevalence rate of noise annoyance among the study population, and finally to evaluate the awareness and practice of workers towards noise hazards.

\section{MATERIALS AND METHODOLOGY}

\section{Subjects}

Two steel factories in United Arab Emirates (UAE) were randomly selected for this cross- sectional study. 468 exposed male workers were randomly selected from a total workforce of 600 from the two steel factories. 270 of the selected workers were from the factory A and the remaining 198 workers from factory B. All the original 468 selected workers were interviewed giving an overall response rate of $100 \%$.

\section{Noise Measurement}

Estimates of noise exposure levels along with concurrent octave band analysis were determined in all work areas in both factories using integrated sound level meter model 
CR:264 which was calibrated before and after each set of measurements. Tripod mounted at a height of $150 \mathrm{~cm}$ from the floor where the workers usually work and measurements were taken at least three times in each area during the period of the study.

Equivalent sound pressure level (Leq) defined as the continuous steady noise level which has the same total acoustic energy as the actual fluctuating noise over the same period of time in (dBA) and sound pressure level (SPL) in $\mathrm{dB}$ were reported. For the purpose of this study, the following two noise exposure levels were defined: low [Leq $\leq 85 \mathrm{~dB}(\mathrm{~A}))$ ] and high [Leq $>85 \mathrm{~dB}(\mathrm{~A}))]$. The latter is the level at which the use of hearing protection devices is required by regulation.

\section{Questionnaire}

A structured interview questionnaire was used to assess the noise annoyance, awareness and practice of workers towards the noise. All interviews were conducted face to face, in English, by a trained research assistant. At the beginning of the interview the objectives of the study were explained to each participant and informed verbal consent was obtained. The subjects were informed that all information collected will be anonymous to secure confidentiality.

\section{Noise Annoyance}

The degree of noise annoyance at the workplace was assessed using the six four-point items (noise annoyance scale) adapted from Samuel et al. [18]. These items were "Does the noise at workplace disturb you?" (1- not at all, 2- little, 3moderate, 4- very much); "How do you feel about the noise level at workplace?" (1- not annoyed at all 2- little, 3- moderate, 4- very annoyed); "Does the noise at workplace make you feel so bad that you feel you cannot carry on working?" (1- not true at all, 2- little, 3- moderate, 4- very true); "Does the noise at workplace prevent you from paying attention to your work?" (1- not at all, 2- little, 3- moderate, 4- very much); "Does the noise at workplace interfere with communicating with other workers (talk, conversation)?" (1- not at all, 2- little, 3- moderate, 4- very much); "Would your general feeling in the workplace improve without the noise?" (1not change at all, 2- little, 3- moderate, 4- it would improve alot).

The Cronbach's alpha and Guttman split-half coefficient were calculated to determine reliability (internal consistency) of this scale. The Cronbach's alpha was 0.74 and Guttman split-half coefficient was 0.82 , indicating that the scale was reliable to assess noise annoyance at the workplace.

Noise annoyance was categorized into four groups: not annoyed, low, moderate, and high corresponding to the quartiles of the score distribution.

\section{Awareness and Practice}

The questionnaire included questions about: Awareness of the workers about the workplace hazards, health problems related to these hazards, effects of noise on health; Hearing protection devices (types and frequency of usage) and demographic characteristics of the study population.
The worker was considered a ware about the hazards associated with his job and their health effects if he mentioned at least two of the hazards and their health effects correctly; aware about effects of noise on health if he mentioned any of the auditory and non-auditory effects correctly; and considered a ware about noise prevention methods if he mentioned any of the noise control measures correctly.

\section{Ethics}

The study was approved by the "Research and Ethical Committee of the College of the Health Sciences - University of Sharjah".

\section{Statistical Analysis}

Data was entered and analyzed using Statistical Package for Social Science 14.0 (SPSS). Frequencies, percentages, means and standard deviations were calculated for appropriate variables. T-Test was used to evaluate possible differences between means of two groups. The chi-square test was used to test differences between qualitative variables. Logistic regression analysis was used to determine the most important factors (predictors) that influence the workers to use hearing protection devises. The dependent variable was use of hearing protection devices $[$ yes $=1$, no $=0$ ], and the independent variables used were noise $[\leq 85 \mathrm{~dB}(\mathrm{~A}),>85 \mathrm{~dB}(\mathrm{~A})]$; age $[<35, \geq 35$ years]; education $[<10, \geq 10$ years]; duration of service $[<5, \geq 5$ years], and noise annoyance [no and low versus moderate and high]. A p-value of less than 0.05 was taken as the statistical level of significance.

\section{RESULTS}

\section{Demographics and Characteristics}

Table 1, shows the demographics characteristics of the study population. The age of the workers ranged from 20 to 52 years with the mean age of 31.6 and SD (7.4) years. The majority $64.9 \%$ (304 subjects) of the study population were less than 35 years of age and only $8.1 \%$ (38 workers) of 45 years old or more. T-test showed that no significant difference between workers in the two steel factories in respect to mean age $(\mathrm{p}=0.197)$. The majority $(55.1 \%)$ of workers were of Indian origin, $38.2 \%$ of Bangladeshi origin and $6.6 \%$ were of Nepali or Pakistani origin. The distribution of the workers according to their education was: $14.3 \%$ literate, 35 $\%$ primary school, $46.4 \%$ secondary school and $4.3 \%$ university education. No significant difference between workers in the Steel factory A and B in regard to mean years of education $(p=0.101)$. The majority of the workers $63.0 \%$ had a current duration of service of less than 5 years and none of the workers had a current duration of service of 15 years or more. Workers from Steel factory B had a significantly higher mean duration of service than those from Steel factory $\mathrm{A}(\mathrm{p}=0.001)$.

\section{Noise Exposure Assessment}

The results of the noise measurements showed that, the equivalent sound pressure level in both factories ranged between 70 Leq $\mathrm{dB}(\mathrm{A})$ and $96 \mathrm{Leq} \mathrm{dB}(\mathrm{A})$, and the sound pressure level varied from $76 \mathrm{~dB}$ to $101 \mathrm{~dB}$ (Table 2). 
Table 1. Demographics and Characteristics of Study Population

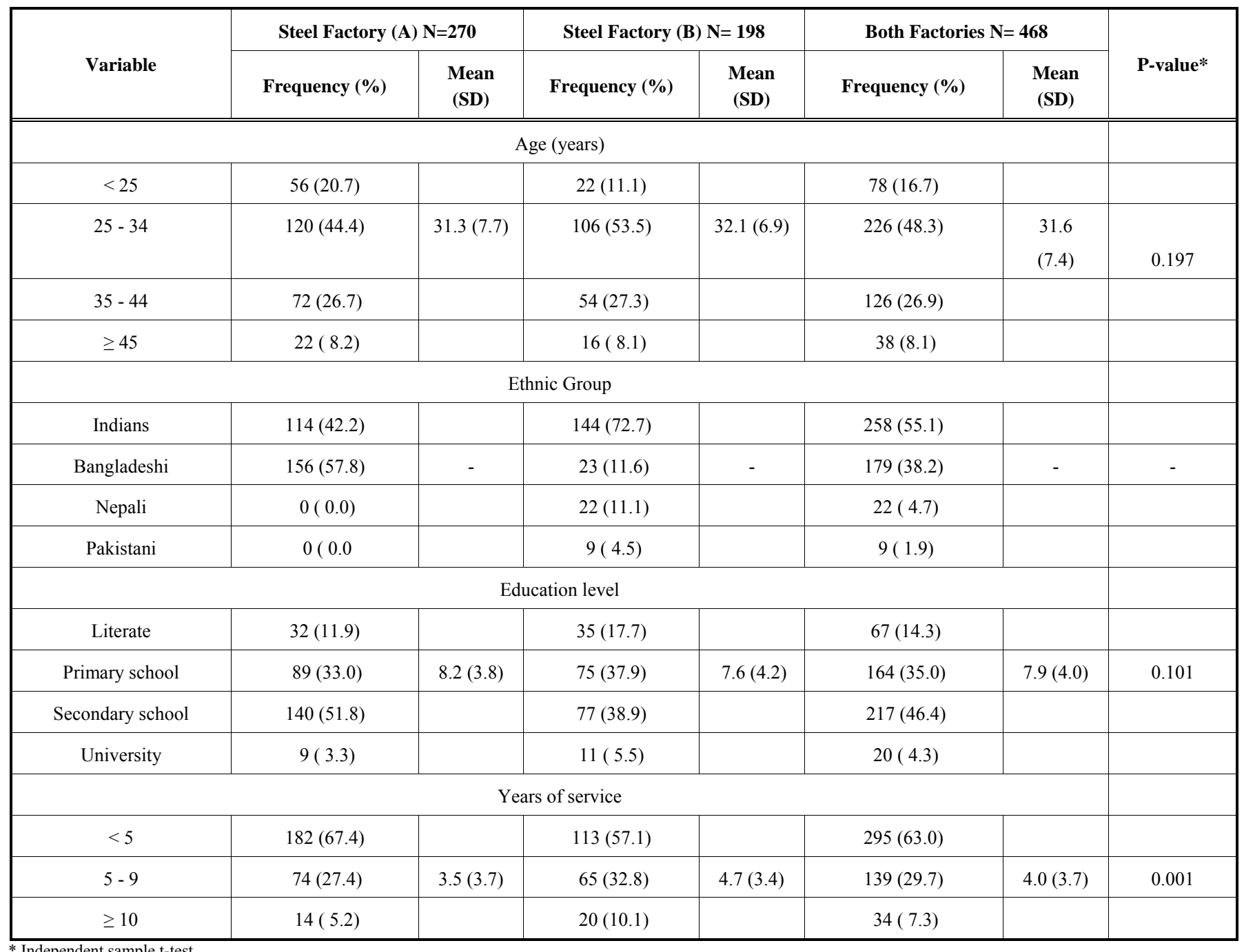

* Independent sample t-test

The noise levels exceeded the $85 \mathrm{~dB}$ (A) criterion recommended by the American Conference of Governmental Industrial Hygienists (USA-ACGIH) [10] in four out of the nine areas in Steel factory A and in six out of the eight areas of Steel factory B. Four hundreds and sixteen workers (88.9 $\%)$ of the study population exposed to a daily Leq above the permissible level of exposure which is $85 \mathrm{~dB}(\mathrm{~A}), 233(56 \%)$ workers of them from Steel factory A. 168 (35.9\%) workers from the two factories exposed to a daily Leq above the maximum exposure limit specified by Occupational Safety and Health Administration (OSHA) which is $90 \mathrm{~dB}$ (A) [11]. The results of the octave band analysis showed that for most areas in both factories the noise was either wide band or of mid - frequency type.

\section{Noise Annoyance}

As shown in Table 3, approximately $80 \%$ of the workers experienced a certain degree of noise annoyance, and more than half of them from the factory A. However, out of the 374 workers who claimed noise annoyance, $117(31.3 \%)$ and $154(41.2 \%)$ workers said they were highly and moderately annoyed by noise respectively and the remaining 103 $(27.5 \%)$ workers reported low noise annoyance. About $51 \%$ and $65 \%$ of the annoyed workers were among the age group 25-34 year and worked for less than 5 years respectively.

The chi-square test showed there was an association between noise annoyance and noise level and the percentage of the workers who reported high or moderate annoyance (264, $97.4 \%$ ) and exposed to a noise level above $85 \mathrm{~dB}$ (A) was significantly higher than the percentage of their counterparts $(7,2.6 \%)$ who exposed to a noise level at or below $85 \mathrm{~dB}$ (A) $(\mathrm{p}<0.001)$.

\section{Awareness and Practice}

As shown in Table 4, $38 \%$ (178 workers) of the total workers reported that, they were aware about the hazards associated with their current jobs. The most commonly mentioned hazards were: falling materials, hot objects, and machines such as cutting machines. The majority (91\%, $162 \backslash 178$ ) of them agreed that exposure to these hazards was serious to their health. 
Table 2. The Overall Noise Level in Each of the Steel Factory by Area

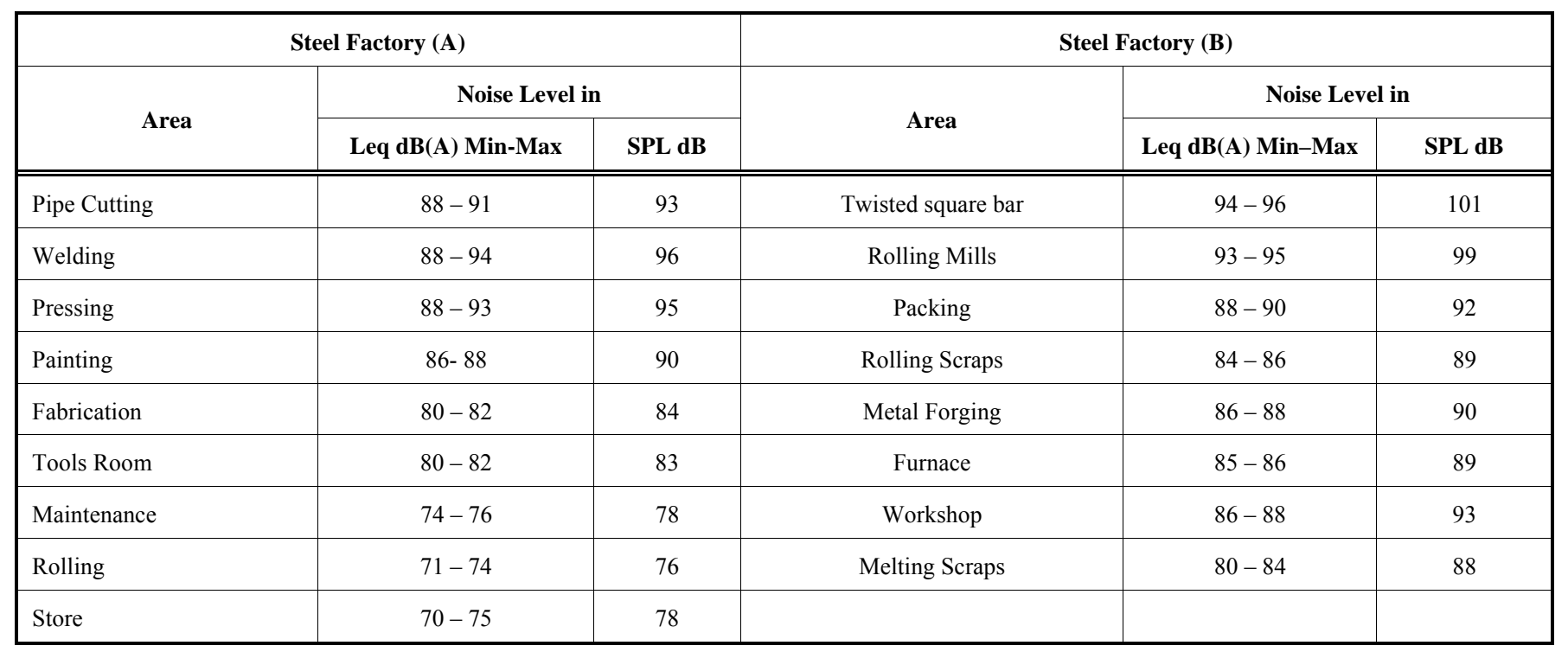

Table 3. Prevalence of Noise Annoyance among Steel Workers

\begin{tabular}{|c|c|c|c|c|c|c|}
\hline Degree of noise Annoyance (Score) & \multicolumn{2}{|c|}{ Steel Factory(A) $N=270$} & \multicolumn{2}{|c|}{ Steel Factory $(B) N=198$} & \multicolumn{2}{|c|}{ Both Factories N=468 } \\
\hline Low (7-8) & 69 & $(25.6)$ & 34 & $(17.2)$ & 103 & $(22.0)$ \\
\hline $\operatorname{High}(>11)$ & 55 & $(20.4)$ & 62 & $(31.3)$ & 117 & $(25.0)$ \\
\hline
\end{tabular}

Few workers $(4.1 \%)$ said they were aware about the health effects of noise and only $(1.9 \%)$ of study population knew the safety measures that they should take to protect themselves from the noise at the workplace. When workers asked about the source of their information about hazards associated with their current jobs, $28(6.0 \%)$ workers reported being ever informed about occupational hazards either from previous or current employer. $12.2 \%$ of the workers said they attended a training course about occupational health and safety during their current or previous jobs.

As presented in Table 5, workers informed about the hazards and those attended a training course about occupational health and safety were significantly more aware about: the types and health effects of the job-associated hazards $(p=$ 0.001 and $p=0.001$ respectively); the health effects of the noise ( $\mathrm{p}=0.021$ and $\mathrm{p}=0.019$ respectively) than workers who never informed and those never attended a training course. However, regarding the safety measures, workers informed about the hazards were significantly more aware than those who never informed $(p=0.013)$, but no significant difference between workers attended and those never attended a training course about occupational health and safety $(\mathrm{p}=0.301)$.

All the workers who stated awareness about the jobassociated hazards and their health effects, in addition, to those agreed that noise was a serious hazard and claimed awareness about safety measures were exposed to a daily Leq above the permissible level of exposure which is $85 \mathrm{~dB}$ (A).

The hearing protection devices available for workers in both factories were ear plugs and ear muffs. As shown in Fig. (1), only $13.2 \%$ (62 workers) indicated that they used the hearing protection devices all the time, the majority of them $(88.7 \%)$ in factory A. Approximately $40 \%$ (187 workers) used hearing protection devices sometimes, the majority of them $(66.8 \%)$ from the factory A. Two hundred and nineteen workers $(46.8 \%)$ said never used hearing protection devices, the majority of them (58.9\%) from factory B. Fiftysix $(90.3 \%)$ out of the 62 workers who reported using devices all the time were found to be wearing them on a surprise spot check on the factory floor. For the statistical analysis the workers were dichotomized into hearing protection device users (all the time and sometimes; $\mathrm{N}=249$ ) and non-users (never used; $\mathrm{N}=219$ ).

Hearing protection device users said the devices were not comfortable, or hindering them during their jobs, or interfering with their communication while wearing them. While, the non-users mentioned no need or discomfort as reasons. 
Table 4. Distribution of the Workers According to their Responses to Awareness Questions, Receiving Information, and Training.

\begin{tabular}{|c|c|c|c|c|c|c|}
\hline \multirow{2}{*}{ Question } & \multicolumn{2}{|c|}{ Steel Factory (A) $N=270$} & \multicolumn{2}{|c|}{ Steel Factory (B) N= 198} & \multicolumn{2}{|c|}{ Both Factories $N=468$} \\
\hline & Yes (\%) & No (\%) & Yes (\%) & No (\%) & Yes (\%) & No (\%) \\
\hline Awareness about job-associated hazards & $85(31.5)$ & $185(68.5)$ & $93(47.0)$ & $105(53.0)$ & $178(38.0)$ & $290(62.0)$ \\
\hline $\begin{array}{l}\text { Awareness about health effects of job-associated } \\
\text { hazards }\end{array}$ & $76(28.1)$ & 194(71.9) & $86(43.4)$ & $112(56.6)$ & $162(34.6)$ & $306(65.4)$ \\
\hline Awareness about effects of noise on health & $6(2.2)$ & $264(97.8)$ & $13(6.6)$ & $185(93.4)$ & $19(4.1)$ & $449(95.9)$ \\
\hline Awareness about noise prevention methods & $3(1.1)$ & $267(98.9)$ & $6(3.0)$ & 192(97.0) & $9(1.9)$ & $459(98.1)$ \\
\hline Ever informed about job-associated hazards & $0(0)$ & $270(100)$ & $28(14.1)$ & $170(85.9)$ & $28(6.0)$ & $440(94.0)$ \\
\hline $\begin{array}{l}\text { Ever attended a training course about occupational } \\
\text { health and safety }\end{array}$ & $0(0)$ & $270(100)$ & $57(28.8)$ & $141(71.2)$ & $57(12.2)$ & $411(87.8)$ \\
\hline
\end{tabular}

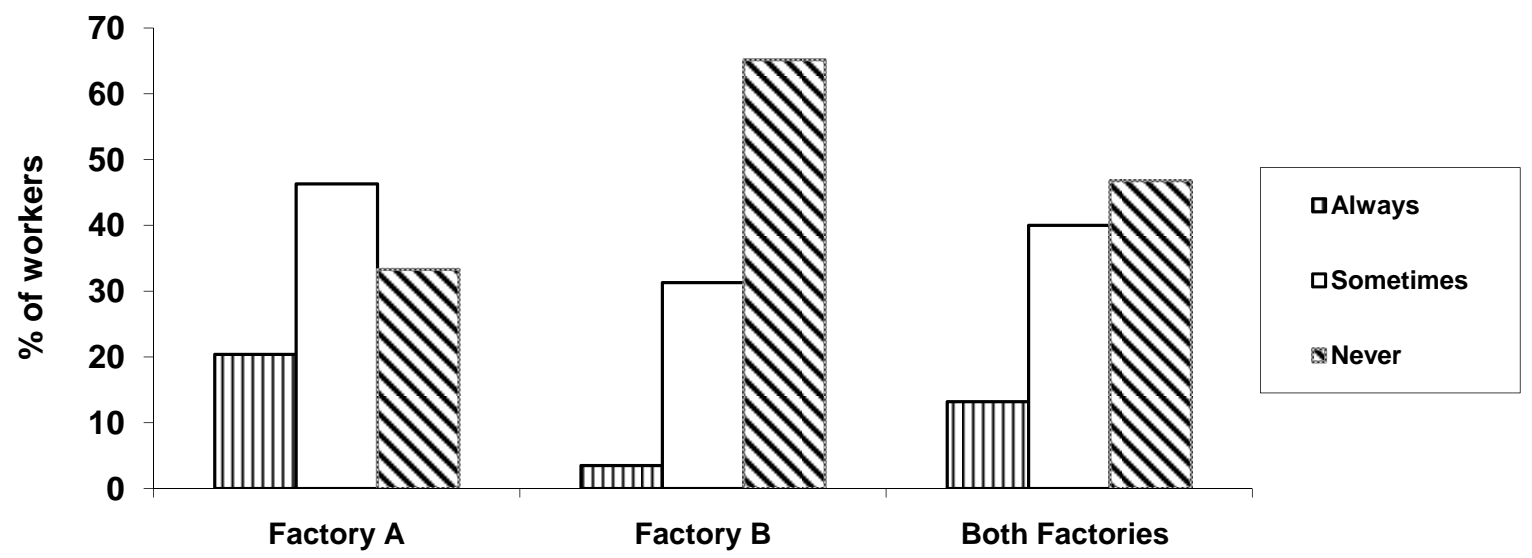

Fig. (1). Use of Hearing Protection Devices.

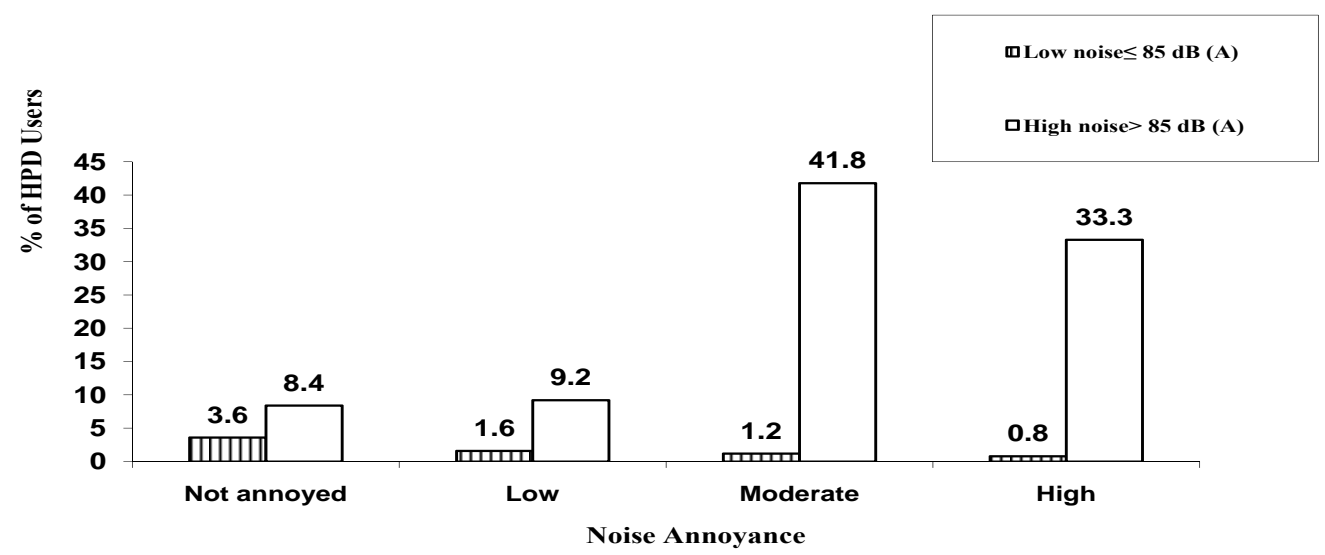

Fig. (2). Use of Hearing Protection Devices by noise annoyance and noise exposure level.

About $93 \%$ of hearing protector users exposed to a noise level above $85 \mathrm{~dB}$ (A). Unexpectedly about $45 \%$ of the workers exposed to a noise level above $85 \mathrm{~dB}$ (A) never used hearing protection devices.

As shown in Table 6, the use of hearing protection devices was positively related to the noise level $(p=0.005)$, indicating that workers exposed to high noise level used hearing protection devices more often compared with those exposed to low noise level. Also there was an association between the use of hearing protection devices and noise annoyance $(p=0.001)$. However, there was no association between the use of hearing protection devices and the years of education $(p=0.517)$, age $(p=0.923)$, and years of service $(\mathrm{p}=0.702)$.

Two hundred and nineteen workers (88\%) of the hearing protection device users said they were annoyed by noise. About $96 \%$ (210 workers) of them exposed to a noise level 
Table 5. Association between the Awareness's Questions, Informed about Hazards, and Attending Training Course

\begin{tabular}{|c|c|c|c|c|}
\hline \multirow[t]{2}{*}{ Question } & \multicolumn{2}{|c|}{$\begin{array}{c}\text { Ever Informed About Job-associated } \\
\text { Hazards }\end{array}$} & \multicolumn{2}{|c|}{$\begin{array}{l}\text { Ever Attended a Training Course About } \\
\text { Occupational Health and Safety }\end{array}$} \\
\hline & Yes (\%) & No (\%) & Yes $(\%)$ & No (\%) \\
\hline \multicolumn{5}{|l|}{ Awareness about job-associated hazards } \\
\hline Yes & $25(89.3)$ & $153(34.8)$ & $36(63.2)$ & $142(34.5)$ \\
\hline No & $3(10.7)$ & $287(65.2)$ & $21(36.8)$ & $269(65.5)$ \\
\hline P-value* & \multicolumn{2}{|c|}{0.001} & \multicolumn{2}{|c|}{0.001} \\
\hline \multicolumn{5}{|l|}{ Awareness about health effects of iob-associated hazards } \\
\hline Yes & $24(85.7)$ & $138(31.4)$ & $35(61.4)$ & $127(30.9)$ \\
\hline No & $4(14.3)$ & $302(68.6)$ & $22(38.6)$ & $284(69.1)$ \\
\hline P-value* & \multicolumn{2}{|c|}{0.001} & \multicolumn{2}{|c|}{0.001} \\
\hline \multicolumn{5}{|l|}{ Awareness about effects of noise on health } \\
\hline Yes & $4(14.3)$ & $15(3.4)$ & $6(10.5)$ & $13(3.2)$ \\
\hline No & $24(85.7)$ & $425(96.6)$ & $51(89.5)$ & $398(96.8)$ \\
\hline P-value* & \multicolumn{2}{|c|}{0.021} & \multicolumn{2}{|c|}{0.019} \\
\hline \multicolumn{5}{|l|}{ Awareness about noise prevention methods } \\
\hline Yes & $3(10.7)$ & $6(1.4)$ & $2(3.5)$ & $7(1.7)$ \\
\hline No & $25(89.3)$ & $434(98.6)$ & $55(96.5)$ & $404(98.3)$ \\
\hline P-value* & \multicolumn{2}{|c|}{0.013} & \multicolumn{2}{|c|}{0.301} \\
\hline
\end{tabular}

* Fisher's Exact Test

Table 6. Use of Hearing Protection Devices in Relation to Noise Level, Age, Education, Service, and Annoyance

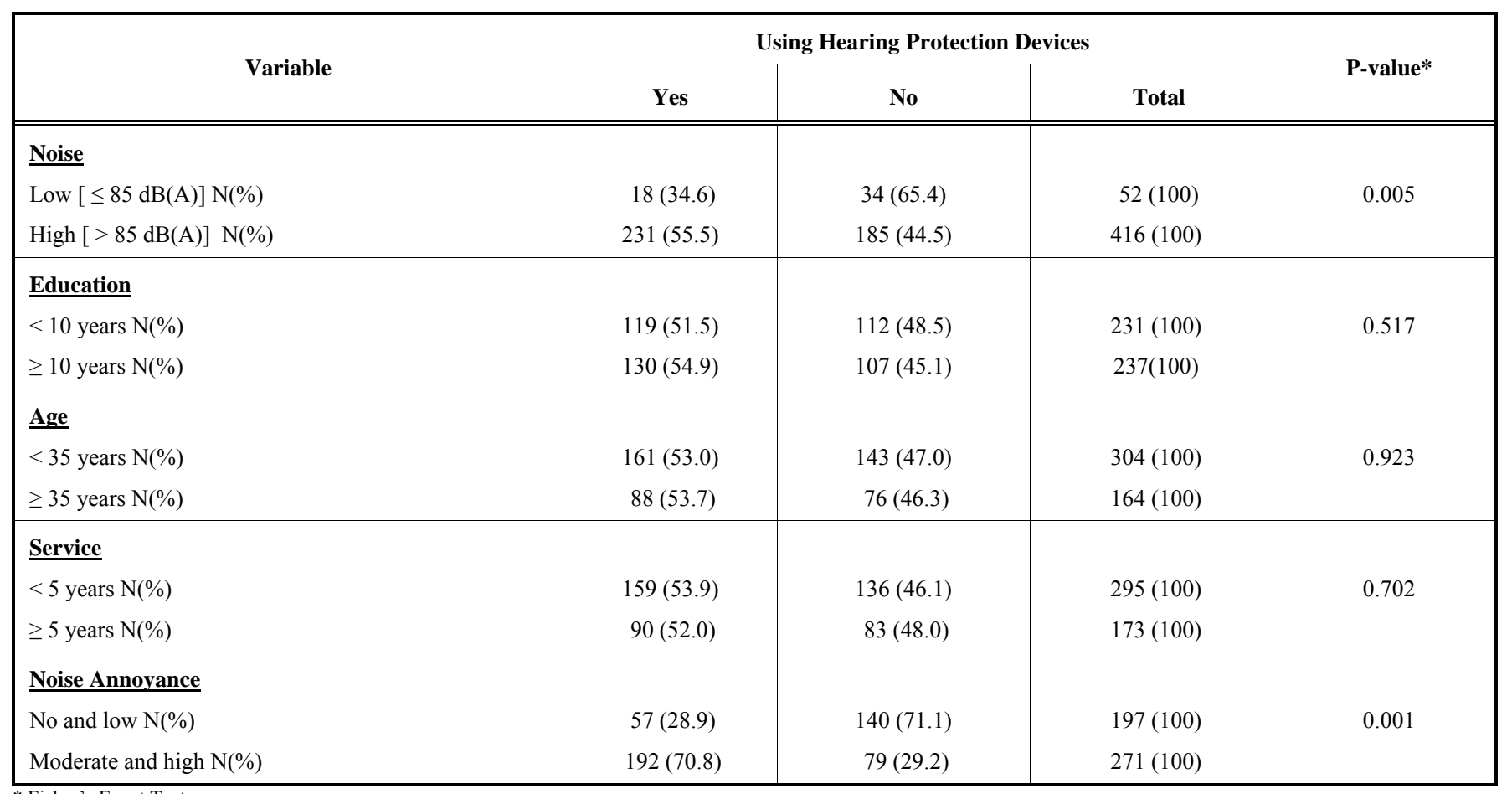

* Fisher's Exact Test

above $85 \mathrm{~dB}(\mathrm{~A})$ and the remaining $4 \%$ (9 workers) exposed to a noise level at or below $85 \mathrm{~dB}(\mathrm{~A})$.
The breakdown of percentages of hearing protection device users in both noise levels by noise annoyance is shown in Fig. (2). This breakdown shows that the majority $77.1 \%$ 
(192 out of 249 workers) of the hearing protection device users were workers highly or moderately annoyed by noise. Among workers exposed to high noise level, the majority $81 \%$ ( 187 out of 231 workers) of the hearing protection device users belonged to the highly or moderately annoyed group. While, among the workers exposed to low noise level the corresponding percentage was only $27.8 \%$ ( 5 out of 18 workers). Interestingly, among the workers exposed to low noise level, $50 \%$ (9out of 18 workers) of noise annoyed workers (low or moderate or high) preferred to use hearing protection devices even though there was no immediate threat to their hearing.

Furthermore, There was association between noise annoyance and use of hearing protection devices among workers exposed to a noise level above $85 \mathrm{~dB}(\mathrm{~A})(\mathrm{p}<0.001)$. No significant association between noise annoyance and hearing protection devices usage among workers exposed to a noise level at or below $85 \mathrm{~dB}(\mathrm{~A})(\mathrm{p}>0.05)$.

Logistic regression analysis revealed that out of the independent variables noise level, age, education, duration of service, and noise annoyance, only noise level $(\mathrm{OR}=2.4$; $95 \% \mathrm{CI}=1.3-4.3)$ or noise annoyance $(\mathrm{OR}=5.6 ; 95 \% \mathrm{CI}=$ 3.5-8.9) could influence the workers to use the hearing protection devices.

\section{DISCUSSION}

Occupational exposure to noise is unavoidable in steel industries, but it could be reduced through effective engineering control measures and/or proper use of appropriate hearing protection devices. However, unlike industrialized countries, effective practice of occupational health and safety has yet to be fully adopted in most of developing countries.

The noise levels reported in this study [70 - 96 Leq $\mathrm{dB}(\mathrm{A})$ ] are consistent with levels that documented in the literature for steel industries $[3,6,12,13]$. In the current study about $40 \%$ of hearing protection device non-users exposed to a daily noise level liable to cause noise induced hearing loss [a daily Leq above $85 \mathrm{~dB}(\mathrm{~A})$ ]. However, the percentage will be even higher, if we take into consideration that the exposure time is at least 48 hours per week in these factories and not 40 hours per week as in the USA and European countries where these standards are adopted.

The finding of this investigation that $(57.9 \%)$ of the steel workers suffering high or moderate noise annoyance and noise annoyance was more among the age group of 25-34 years and exposure group of less than 5 years is consistent with a study carried out in India in small-scale hand tools manufacturing industry and showed that $62 \%$ of workers in forging units annoyed by the noise, and was more among the age group of 30-34 year and exposure group of 3-5 years [13]. Bedi reported low percentage (42\%) of textile workers experienced noise annoyance [14].

Only $57 \%$ of the workers involved in the current study suffering speech interference, whereas, in previous studies $70-95 \%$ of workers have suffered from speech interference $[4,13,14]$.

Awareness of workers about the health effects of occupational exposure to noise plays an important role in prevention of auditory and non-auditory effects. In this investigation, few workers $(4.1 \%)$ claimed awareness about the health effects of noise. In other studies $29-93 \%$ of workers were aware about the health effects of noise [4, 12-14]. Svensson et al. stated that $95 \%$ of the Swedish workers were aware that loud noise could damage their hearing [15]. In addition, one study in Malaysia found that $36 \%$ of the noise exposed workers knew that exposure to excessive noise results in hearing loss [16]. Regarding the safety measures that should be taken to protect workers from noise, almost $2 \%$ of the workers were aware about them in this study, compared with $92 \%$ reported by Ologe et al. [12].

The finding of this study that the majority of the workers had formal education and low duration of service, but few of them were aware about the health effects of noise and the safety measures, supports the conclusion of the previous researchers that awareness appears to be derived from the personal experience of working in a noisy environment for many years, rather than from educational input $[12,17]$.

In this investigation, the variables informed about the job-associated hazards and attending a training course about occupational health and safety were found to be related to the awareness of the workers about the health effects of noise and the safety measures. This study and Ologe et al. study are in agreement that both noise annoyance and awareness were positively related with noise exposure [12].

The finding of this investigation that $53.2 \%$ of the total workers used hearing protection devices, but only about 25 $\%$ of them use them always is similar to another study conducted in Pakistan in the textile industry and reported that 55 $\%$ using hearing protection devices out of which only $25 \%$ were using them continuously [4]. However, other authors reported different figures; Singh LP et al. stated that only 5 $\%$ workers used hearing protection devices always [13]. Ahmed et al. and Samuel et al. reported $7 \%$ and $24 \%$ of workers exposed to noise using hearing protection devices during working hours respectively $[5,18]$. A study in a steel rolling mill in Nigeria reported that hearing protection devices were available to $27 \%$ of workers, but only $28 \%$ of them used them always [12], another study in Malaysia found that only $5 \%$ of the workers provided with hearing protection devices wore them regularly [16].

The finding that about $93 \%$ of those using hearing protection devices (all the time or sometimes) exposed to a noise level higher than $85 \mathrm{~dB}(\mathrm{~A})$ is in agreement with that reported in other studies $[12,18]$. Interestingly, in this study about $35 \%$ out of the workers exposed to low noise level of $85 \mathrm{~dB}(\mathrm{~A})$ or less used hearing protection devices, Samuel et al. reported a lower percentage(19\%) [18].

This study and Samuel et al. study [18] are in agreement that the use of hearing protectors was positively associated with the noise level, but in contrast to Samuel et al. [18], the use of hearing protection devices was not associated with years of education and age in this study.

The most ascribed reasons for non-use of hearing protection devices in this study were no need or discomfort. Others reported uncomfortable, not available and negligence as barriers for not using hearing protection devices [13, 19].

In this investigation, about $84 \%$ of hearing protection users came from annoyed group and exposed to high noise 
level, and a very low percentage (3.6\%) of hearing protection devices users came from annoyed group and exposed to low noise level, whereas Samuel et al. reported different percentages $61 \%$ and $60 \%$ respectively [18].

The findings of the current study that use of hearing protection devices and noise annoyance were dependent; and there was a positive association between noise annoyance and hearing protection device usage among workers exposed to high noise levels is consistent with that reported by Samuel et al. [18], and supporting their suggestion that the factor noise annoyance should be incorporated into all future studies on the use of hearing protection devices. In contrast to Samuel et al. [18] no association found between the noise annoyance and hearing protection devices usage among workers exposed to a noise level at or below $85 \mathrm{~dB}(\mathrm{~A})$.

\section{CONCLUSIONS}

The findings of this study have clearly revealed that the workers in both factories are at high risk of developing noise induced hearing (NIHL), noise annoyance, and other related ailments due to excessive occupational exposure to noise, and non-use of hearing protection devices. The majority of the workers unaware about the health effects of noise and methods of prevention and thus very few workers used the hearing protection devices during the working time.

Awareness was positively associated with noise exposure, and there was an association between noise annoyance and noise level and any one of them could influence the workers to use the hearing protection devices.

There is a need to have a hearing conservation program in both factories, its components include; education to raise the awareness of the workers, noise assessment, usage of hearing protection devices; and audiometry or alternatively as recently suggested, appropriate questions addressing noise exposure might be used for screening subjects exposed to high noise levels and those with hearing loss if facilities for an objective assessment of noise and diagnosing noiseinduced hearing loss are not available [5].

\section{ACKNOWLEDGEMENTS}

The author would like to extend his appreciation to management and the workers in the two steel factories, where the study was conducted for their cooperation and to Mr. Akhtar for his help in collecting the data. This research was supported by a grant from the University of Sharjah, Research and Studies Center, Sharjah, UAE (Project No.051018).

\section{CONFLICT OF INTEREST}

The author declares no conflict of interest.

\section{REFERENCES}

[1] Irwin J. Occupational noise-induced hearing loss. Occup Med 1997; 47: 313-5.

[2] Moon YH, Kwon SP. Hearing impairment due to noise in the Kyung-In industrial area in Korea. Yonsei Med J 1976; 17: 30-8.

[3] Ologe FE, Akande TM, Olajide TG. Occupational noise exposure and sensorineural hearing loss among workers of a steel rolling mill. Eur Arch Otorhinolaryngol 2006; 263: 618- 21.

[4] Ashraf HD, Younus MA, Kumar P, Siddiqui MT, Ali SS, Siddiqui MI. Frequency of hearing loss among textile industry workers of weaving unit in Karachi, Pakistan. J Pak Med Assoc 2009; 59: 5759.

[5] Ahmed HO, Dennis JH, Badran O, et al. Occupational noise exposure and hearing loss of workers in two plants in eastern Saudi Arabia. Ann Occup Hyg 2001; 45: 371-80.

[6] Harmadji S, Kabullah H. Noise induced hearing loss in steel factory workers. Folia Med Indones 2004; 40:171-4.

[7] Cuesdan L, Teganeanu S, Tutu C, Raiciu M, Carp C, Coatu S. Study of cardiovascular and auditory pathophysiological implications in a group of operatives working in noisy industrial settings. Psychophysiology 1977; 14: 53-61.

[8] Wu TN, Chou FS, Chang PY. A study of noise-induced hearing loss and blood pressure in steel mill workers. Int Arch Occup Environ Health 1987; 59: 529-36.

[9] Federal law No (24) of 1999 for the protection and development of the environment. [Online], [cited 15 December 2011]. Available from: http://www.moew.gov.ae/En/federallaws

[10] American Conference of Governmental Industrial Hygienists (ACGIH). TLVs and BEIs. Threshold limit values for chemical substances and physical agents, and biological exposure indices. Cincinnati OH: USA 2000.

[11] Occupational safety and Health Administration (OSHA). Occupational noise exposure. Standard No.1926.52. [Online], [cited 15 December 2011]. Available from: http://www.osha.gov

[12] Ologe FE, Akande TM, Olajide TG. Noise exposure, awareness, attitudes and use of hearing protection in a steel rolling mill in $\mathrm{Ni}$ geria. Occup Med 2005; 55: 487-9.

[13] Singh LP, Bhardwaj A, Deepak KK, Bedi R. Occupational noise exposure in small scale hand tools manufacturing (forging) industry (SSI) in northern India. Ind Health 2009; 47: 423-30.

[14] Bedi R. Evaluation of occupational environment in two textile plants in northern India with specific reference to noise. Ind Health 2006; 44: 112-6.

[15] Svensson EB, Morata TC, Nylen P, Krieg EF, Johnson AC. Beliefs and attitudes among Swedish workers regarding the risk of hearing loss. Int J Audiol 2004; 43: 585-93.

[16] Maisarah SZ, Said H. The noise exposed factory workers: the prevalence of sensorineural hearing loss and their use of personal hearing protection devices. Med J Malaysia 1993; 48: 280-5.

[17] Kahan E, Ross E. Knowledge and attitudes of a group of South African mine workers towards noise induced hearing loss and the use of hearing protective devices. S Afr J Commun Disord 1994; 41: 37- 47 .

[18] Samuel M, Rabinowitz S, Green MS. Noise exposure, noise annoyance, use of hearing protection devices and distress among bluecollar workers. Scand J Work Environ Health 1994; 20: 294-300.

[19] Hansia MR, Dickinson D. Hearing protection device usage at a South African gold mine. Occup Med 2009; 60: 72-4. 